\title{
Seizures Prior to Whole-brain Irradiation for Metastatic Disease: Prevalence, Risk Factors and Association With Survival
}

\author{
DIRK RADES ${ }^{1}$, JASPAR WITTELER ${ }^{1}$, LIESA DZIGGEL ${ }^{1}$, \\ TROELS W. KJAER ${ }^{2}$, SOEREN TVILSTED ${ }^{3}$ and STEVEN E. SCHILD ${ }^{4}$ \\ ${ }^{1}$ Department of Radiation Oncology, University of Lübeck, Lübeck, Germany; \\ ${ }^{2}$ Neurological Department, Zealand University Hospital, Roskilde, Denmark; \\ ${ }^{3}$ Research Projects and Clinical Optimization, Zealand University Hospital, Koege, Denmark; \\ ${ }^{4}$ Department of Radiation Oncology, Mayo Clinic, Scottsdale, AZ, U.S.A.
}

\begin{abstract}
Background/Aim: Seizures are a serious condition for patients with brain metastases. Prevalence, risk factors and a potential association of seizures with survival prior to whole-brain irradiation (WBI) for cerebral metastases were retrospectively investigated. Patients and Methods: In 1,934 patients, the prevalence of pre-treatment seizures (pre-WBI) was determined. Seven pre-treatment characteristics were evaluated for associations with seizures. Ten characteristics including pre-treatment symptoms (none vs. seizures only vs. seizures+others vs. others only) and seizures (yes vs. no) were analyzed for survival. Results: In 251 patients (13.0\%), pretreatment seizures were documented. The occurrence of seizures was significantly associated with 1-3 brain metastases and lack of extra-cerebral spread. On multivariate analysis, age, gender, performance score, number of metastases and extra-cerebral spread were significantly associated with survival; pre-treatment symptoms and seizures showed associations on univariate but not on multivariate analyses. Conclusion: Few brain metastases and lack of extra-cerebral spread were independent risk factors for pre-treatment seizures. Seizures appeared positively associated with survival.
\end{abstract}

Depending on the type of primary tumor, brain metastases are diagnosed in up to $40 \%$ of adult cancer patients during the

This article is freely accessible online.

Correspondence to: Prof. Dirk Rades, MD, Department of Radiation Oncology, University of Lübeck, Lübeck, Ratzeburger Allee 160, 23562 Lübeck, Germany. Tel.: +49 45150045401, Fax: +49 45150045404, e-mail: dirk.rades@uksh.de

Key Words: Seizures, brain metastases, whole-brain irradiation, prevalence, risk factors, survival. course of their malignant disease (1). Many of these patients receive whole-brain irradiation (WBI), particularly patients with more than three lesions and patients with a reduced performance status. Seizures were identified as a condition that causes significant impairment in quality of life $(2,3)$. However, the figures regarding the prevalence of pretreatment seizures vary in the literature and range between $12 \%$ and $35 \%(3-10)$. The rate of brain metastasis-related seizures has decreased in the era of magnetic resonance imaging due to earlier detection of the lesions, when they are still asymptomatic (10). Moreover, disagreement exists regarding potential risk factors for seizures $(3,5,7,8)$. The identification of such risk factors is important. Prophylactic administration of anti-epileptic drugs does not appear to result in a reduction of seizures in patients with brain metastases, but selected high-risk patients may benefit from prophylactic treatment (3). Another issue that needs further clarification is the potential prognostic role of pre-treatment seizures for survival. Prognostic factors for survival are important for optimal personalization of cancer treatment (11-17). The present analysis was performed to assess these important issues related to pre-treatment seizures. It was performed in a large cohort of patients treated with a single type of radiotherapy, namely WBI alone, in order to reduce the risk of bias caused by the selection of the radiotherapy type.

\section{Patients and Methods}

A total of 1,934 patients treated with WBI alone for brain metastases between 1991 and 2018 were included in this retrospective study. The study was approved by the ethic committee of the University of Lübeck (reference number: 20-120A).

In this cohort, the prevalence of seizures prior to the initiation of WBI was determined. In addition, seven pre-treatment characteristics were evaluated for associations with occurrence of seizures. These characteristics included age at WBI $(\leq 62 v s . \geq 63$ 
Table I. Patient characteristics investigated within this study.

\begin{tabular}{lc}
\hline Characteristic & Number of patients $(\%)$ \\
\hline Pre-treatment symptoms & \\
No symptoms & $167(9)$ \\
Seizures only & $125(6)$ \\
Seizures+other symptoms & $126(7)$ \\
Other symptoms only & $1,516(78)$ \\
Radiation program & \\
$5 \times 4$ Gy & $400(21)$ \\
$10 \times 3$ Gy & $972(50)$ \\
$14-20 \times 2-2.5$ Gy & $562(29)$ \\
Age & \\
$\leq 62$ Years & $961(50)$ \\
$\geq 63$ Years & $973(50)$ \\
Gender & \\
Female & $931(48)$ \\
Male & $1,003(52)$ \\
ECOG performance score & \\
$0-1$ & $720(37)$ \\
$\geq 2$ & $1,214(63)$ \\
Primary tumor type & \\
Breast cancer & $327(17)$ \\
NSCLC & $803(42)$ \\
SCLC & $274(14)$ \\
RCC & $55(3)$ \\
Melanoma & $77(4)$ \\
CUP & $122(6)$ \\
CRC & $101(5)$ \\
Number types brain metastases & $175(9)$ \\
1 & \\
$2-3$ & $314(16)$ \\
$\geq 4$ & $337(17)$ \\
Extra-cerebral spread & $1,283(66)$ \\
Yes & \\
Interval from first diagnosis of & $1,409(73)$ \\
malignancy until radiotherapy & $525(27)$ \\
$\leq 6$ Months & \\
$\geq 7$ Months & $964(50)$ \\
\hline
\end{tabular}

ECOG: Eastern Cooperative Oncology Group; NSCLC: non-small cell lung cancer; SCLC: small-cell lung cancer; RCC: renal cell carcinoma; CUP: cancer of unknown primary; CRC: colorectal cancer.

years, median age $=63$ years), gender, Eastern Cooperative Oncology Group (ECOG) performance score (0-1 vs. $\geq 2)(18)$, primary tumor type [breast cancer $v s$. non-small cell lung cancer (NSCLC) $v s$. small cell lung cancer (SCLC) vs. renal cell carcinoma (RCC) vs. melanoma $v s$. cancer of unknown primary (CUP) origin $v s$. colorectal cancer (CRC) vs. other types (types with $<50$ patients)], number of brain metastases ( $1 v s .2-3 v s . \geq 4)$, extra-cerebral spread (yes $v s$. no) and interval from first diagnosis of malignancy until radiotherapy of brain metastasis ( $\leq 6 v s . \geq 7$ months, median interval $=7$ months). Moreover, these seven characteristics plus the WBI-program $(5 \times 4$ Gy vs. $10 \times 3$ Gy vs. 14-20×2-2.5 Gy), the type of pre-treatment symptoms (no symptoms $v s$. seizures only $v s$. seizures + other symptoms $v s$. other symptoms only) and pretreatment seizures (yes=seizures only or seizures + other symptoms
Table II. Associations between pre-treatment patient characteristics and pre-treatment seizures.

\begin{tabular}{|c|c|c|}
\hline Characteristic & $\begin{array}{l}\text { Patients with } \\
\text { seizures }\end{array}$ & $p$-Value \\
\hline \multicolumn{3}{|l|}{ Age } \\
\hline$\leq 62$ Years & $142(14.8 \%)$ & \multirow[t]{2}{*}{0.029} \\
\hline$\geq 63$ Years & $109(11.2 \%)$ & \\
\hline \multicolumn{3}{|l|}{ Gender } \\
\hline Female & $111(11.9 \%)$ & \multirow[t]{2}{*}{0.22} \\
\hline Male & $140(14.0 \%)$ & \\
\hline \multicolumn{3}{|c|}{ ECOG performance score } \\
\hline $0-1$ & $112(15.6 \%)$ & \multirow[t]{2}{*}{0.015} \\
\hline$\geq 2$ & $139(11.4 \%)$ & \\
\hline \multicolumn{3}{|c|}{ Primary tumor type } \\
\hline Breast cancer & $40(12.2 \%)$ & \multirow[t]{8}{*}{0.85} \\
\hline NSCLC & $114(14.2 \%)$ & \\
\hline SCLC & $34(12.4 \%)$ & \\
\hline $\mathrm{RCC}$ & $5(9.1 \%)$ & \\
\hline Melanoma & $9(11.7 \%)$ & \\
\hline CUP & $14(11.5 \%)$ & \\
\hline $\mathrm{CRC}$ & $16(15.8 \%)$ & \\
\hline Other types & $19(10.9 \%)$ & \\
\hline \multicolumn{3}{|c|}{ Number of brain metastases } \\
\hline 1 & $62(19.7 \%)$ & \multirow[t]{3}{*}{$<0.001$} \\
\hline $2-3$ & $58(17.2 \%)$ & \\
\hline$\geq 4$ & $131(10.2 \%)$ & \\
\hline \multicolumn{3}{|c|}{ Extra-cerebral spread } \\
\hline Yes & $154(10.9 \%)$ & \multirow[t]{2}{*}{$<0.001$} \\
\hline No & $97(18.5 \%)$ & \\
\hline \multicolumn{3}{|c|}{$\begin{array}{l}\text { Interval from first diagnosis of } \\
\text { malignancy until radiotherapy }\end{array}$} \\
\hline$\leq 6$ Months & $123(12.8 \%)$ & \multirow[t]{2}{*}{0.79} \\
\hline$\geq 7$ Months & $128(13.2 \%)$ & \\
\hline
\end{tabular}

ECOG: Eastern Cooperative Oncology Group; NSCLC: non-small cell lung cancer; SCLC: small-cell lung cancer; RCC: renal cell carcinoma; CUP: cancer of unknown primary; CRC: colorectal cancer; bold $p$ values were significant (After Bonferroni adjustment, $p$-values $<0.007$ were considered significant representing an alpha level $<0.05$ ).

$v s$. no=no symptoms or other symptoms only) were analyzed with respect to survival. The distributions of these characteristics are summarized in Table I.

The analyses regarding the evaluation of the seven pre-treatment characteristics for associations with seizures were performed with the Chi-square test. After applying the Bonferroni adjustment for multiple comparisons ( 7 tests), the $p$-value had to be lowered to 0.007 to consider that a characteristic was significantly associated with the occurrence of pre-treatment seizures at an alpha-level of $<0.05$ (19). p-Values $<0.05$ were considered a trend.

For the univariate analyses regarding survival, the Kaplan-Meier method and the log-rank test were used. Since ten characteristics were included in this analysis (10 tests), $p$-values $<0.005$ were considered significant representing an alpha-level of $<0.05$ after applying the Bonferroni adjustment. Again, $p$-values $<0.05$ were considered a trend. Significant characteristics were additionally evaluated for independence using a Cox regression model, where $p$ values $<0.05$ were considered significant. 
Table III. Results of the univariate analyses of survival following whole-brain irradiation.

\begin{tabular}{|c|c|c|c|c|c|}
\hline Characteristic & At 3 months (\%) & At 6 months (\%) & At 9 months (\%) & At 12 months (\%) & $p$-Value \\
\hline \multicolumn{6}{|l|}{ Pre-treatment symptoms } \\
\hline No symptoms & 49 & 32 & 25 & 21 & \multirow[t]{4}{*}{$<0.001$} \\
\hline Seizures only & 61 & 47 & 42 & 40 & \\
\hline Seizures + others & 41 & 25 & 18 & 13 & \\
\hline Other symptoms only & 48 & 29 & 21 & 14 & \\
\hline \multicolumn{6}{|l|}{ Pre-treatment seizures } \\
\hline Seizures & 51 & 36 & 30 & 26 & \multirow[t]{2}{*}{0.002} \\
\hline No seizures & 48 & 29 & 22 & 15 & \\
\hline \multicolumn{6}{|l|}{ Radiation program } \\
\hline $5 \times 4$ Gy & 57 & 34 & 25 & 18 & \multirow[t]{3}{*}{0.014} \\
\hline $10 \times 3 \mathrm{~Gy}$ & 46 & 27 & 20 & 16 & \\
\hline $14-20 \times 2-2.5$ Gy & 47 & 32 & 25 & 17 & \\
\hline \multicolumn{6}{|l|}{ Age } \\
\hline$\leq 62$ Years & 57 & 38 & 30 & 22 & \multirow[t]{2}{*}{$<0.001$} \\
\hline$\geq 63$ Years & 39 & 23 & 16 & 11 & \\
\hline \multicolumn{6}{|l|}{ Gender } \\
\hline Female & 51 & 34 & 27 & 21 & \multirow[t]{2}{*}{$<0.001$} \\
\hline Male & 46 & 26 & 19 & 12 & \\
\hline \multicolumn{6}{|l|}{ ECOG performance score } \\
\hline $0-1$ & 66 & 49 & 40 & 31 & \multirow[t]{2}{*}{$<0.001$} \\
\hline$\geq 2$ & 38 & 19 & 13 & 8 & \\
\hline \multicolumn{6}{|l|}{ Primary tumor type } \\
\hline Breast cancer & 57 & 41 & 35 & 28 & \multirow[t]{8}{*}{$<0.001$} \\
\hline NSCLC & 44 & 30 & 23 & 17 & \\
\hline SCLC & 48 & 26 & 18 & 11 & \\
\hline $\mathrm{RCC}$ & 62 & 33 & 28 & 22 & \\
\hline Melanoma & 45 & 27 & 16 & 6 & \\
\hline CUP & 45 & 26 & 18 & 13 & \\
\hline $\mathrm{CRC}$ & 39 & 20 & 16 & 9 & \\
\hline Other types & 54 & 28 & 18 & 14 & \\
\hline \multicolumn{6}{|c|}{ Number of brain metastases } \\
\hline 1 & 55 & 41 & 32 & 27 & \multirow[t]{3}{*}{$<0.001$} \\
\hline $2-3$ & 59 & 40 & 34 & 25 & \\
\hline$\geq 4$ & 44 & 25 & 18 & 12 & \\
\hline \multicolumn{6}{|l|}{ Extra-cerebral spread } \\
\hline Yes & 41 & 22 & 16 & 11 & \multirow[t]{2}{*}{$<0.001$} \\
\hline No & 67 & 50 & 41 & 32 & \\
\hline \multicolumn{6}{|c|}{ Interval from diagnosis of malignancy until RT } \\
\hline$\leq 6$ Months & 45 & 29 & 21 & 15 & \multirow[t]{2}{*}{0.007} \\
\hline$\geq 7$ Months & 51 & 32 & 25 & 18 & \\
\hline
\end{tabular}

RT: Radiotherapy; ECOG: Eastern Cooperative Oncology Group; NSCLC: non-small cell lung cancer; SCLC: small-cell lung cancer; RCC: renal cell carcinoma; CUP: cancer of unknown primary; CRC: colorectal cancer, bold $p$-values were significant (After Bonferroni adjustment; $p$-values $<0.005$ were considered significant representing an alpha level $<0.05)$.

\section{Results}

In 251 of the 1,934 patients ( $13.0 \%)$, seizures were documented prior to the initiation of WBI. In the corresponding analysis (Table II), a significant association between a characteristic and pre-treatment seizures was found for a limited number of 1-3 brain metastases $(p<0.001)$ and absence of extra-cerebral spread $(p<0.001)$. In addition, age $\leq 62$ years $(p=0.029)$ and an ECOG performance score of $0-1(p=0.015)$ showed trends.

On univariate analyses of survival (Table III), a significant association between a characteristic and outcome was observed for pre-treatment symptoms ( $p<0.001$, Figure 1), pre-treatment seizures $(p=0.002$, Figure 2$)$, age $(p<0.001)$, gender $(p<0.001)$, ECOG performance score $(p<0.001)$, primary tumor type $(p<0.001)$, number of metastases $(p<0.001)$ and extra-cerebral spread $(p<0.001)$. In addition, trends were found for the WBIprogram $(p=0.014)$ and the interval from first diagnosis of the malignancy and WBI $(p=0.007)$.

In the subsequent Cox regression analysis (Table IV), age $(p<0.001)$, gender $(p<0.001)$, ECOG performance score $(p<0.001)$, number of metastases $(p<0.001)$ and extracerebral spread $(p<0.001)$ maintained significance and were 


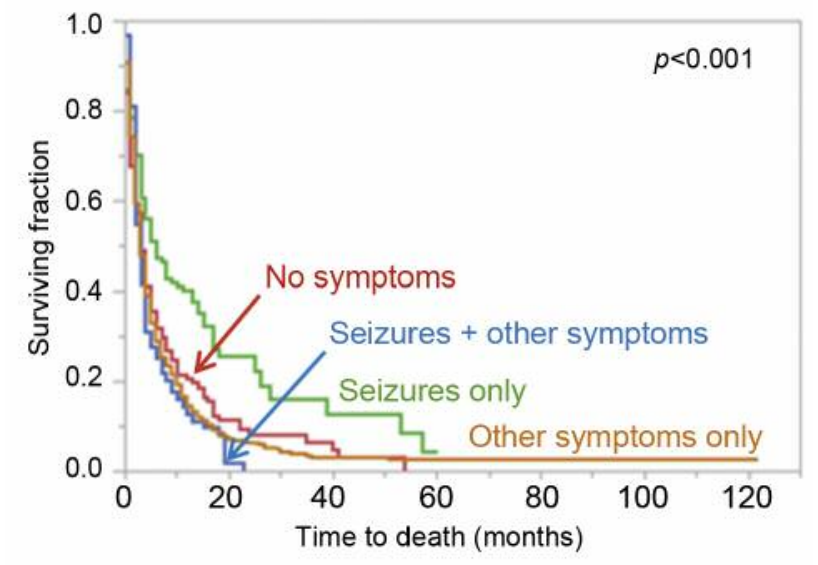

Figure 1. Kaplan-Meier curves related to the different types of pretreatment symptoms, namely no symptoms $(n=167)$, seizures only $(n=125)$, seizures+other symptoms $(n=126)$ and other symptoms only $(n=1,516)$.

considered independent predictors of survival. Type of pretreatment symptoms $(p=0.79)$ and type of primary tumor $(p=0.97)$ were not significant. Since type of pre-treatment symptoms and pre-treatment seizures were confounding variables, a second multivariate analysis was performed including pre-treatment seizures instead of pre-treatment symptoms. In this analysis, pre-treatment seizures did not achieve significance $(p=0.99)$. The results regarding the other characteristics were very similar to the first multivariate analysis.

\section{Discussion}

Brain metastases are more common in oncology than primary brain tumors and can be associated with significant symptoms (1). One of these symptoms is seizures that can have a negative impact on the patients' quality of life, as previously described for patients with primary brain tumors $(20,21)$. In the literature, the prevalence of seizures in patients with brain metastases ranges between $12 \%$ and $35 \%$ (3-10). This may be a result of variations between the cohorts of these studies with respect to patient characteristics including the number of cerebral lesions and primary tumor types. The treatment for brain metastases varies with respect to these two characteristics. Many patients with a single lesion receive neurosurgical resection or radiosurgery with or without WBI. Most patients with very few lesions especially with less radiosensitive tumors such as RCC and melanoma receive radiosurgery. The majority of patients with brain metastases from SCLC, a poor performance status, and/or many lesions receive WBI alone (1). Moreover, the treatment itself can increase or decrease the occurrence of seizures $(2,3,7)$.

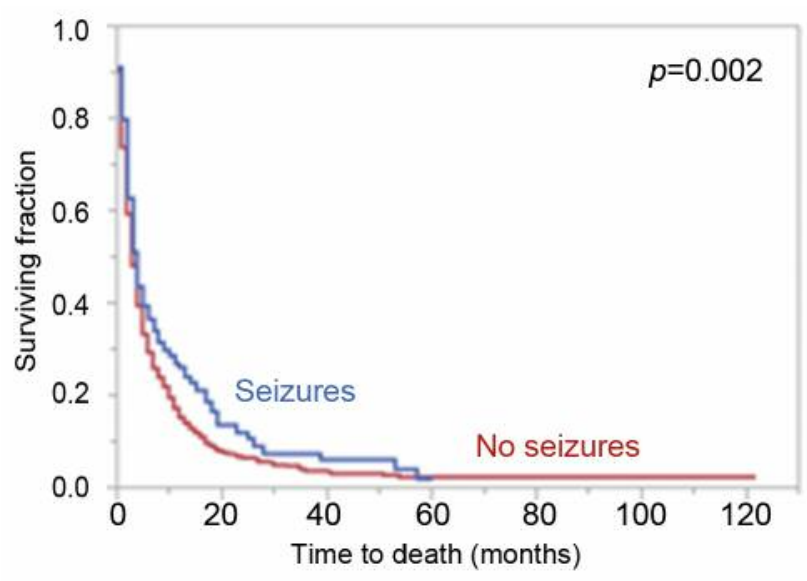

Figure 2. Kaplan-Meier curves related to pre-treatment seizures ( seizures only or seizures + other symptoms, $n=251$ ) or no pre-treatment seizures (no symptoms or other symptoms only, $n=1,683$ ).

Table IV. Results of the multivariate analyses with the Cox regression model.

\begin{tabular}{lccc}
\hline Factor & $\begin{array}{c}\text { Risk } \\
\text { ratio }\end{array}$ & $\begin{array}{c}95 \% \text {-Confidence } \\
\text { interval }\end{array}$ & $p$-Value \\
\hline Type of pre-treatment symptoms & 1.01 & $0.95-1.06$ & 0.79 \\
Pre-treatment seizures* & 1.00 & $0-86-1.16$ & 0.99 \\
Age & 1.34 & $1.21-1.47$ & $\mathbf{< 0 . 0 0 1}$ \\
Gender & 1.21 & $1.10-1.34$ & $\mathbf{< 0 . 0 0 1}$ \\
ECOG performance score & 1.84 & $1.64-2.06$ & $\mathbf{< 0 . 0 0 1}$ \\
Primary tumor type & 1.00 & $0.98-1.02$ & 0.97 \\
Number of brain metastases & 1.08 & $1.03-1.13$ & $\mathbf{< 0 . 0 0 1}$ \\
Extra-cerebral spread & 1.72 & $1.53-1.94$ & $\mathbf{< 0 . 0 0 1}$ \\
\hline
\end{tabular}

ECOG: Eastern Cooperative Oncology Group; *data obtained from an additional multivariate analysis; bold values indicate significant $p$ values.

To avoid a bias due to the type of treatment selected, the present study focused on patients who did not receive local therapy such as neurosurgery or radiosurgery but received WBI alone. Moreover, it investigated pre-treatment seizures to exclude a bias caused by treatment-associated effects. According to previous studies, a bias due to the interval between diagnosis of brain metastases and start of WBI appeared very unlikely $(22,23)$.

In the present cohort of 1,934 patients, the prevalence of pre-treatment seizures was $13.0 \%$. This rate was within the range of $12-35 \%$ reported in the literature but at the lower end (3-10). This may be explained by the fact that the proportion of patients with melanoma, which has been reported to be the tumor type with the highest rate of seizures, was low, i.e. only $4 \%$, and the cumulative proportion of the low-risk tumors breast cancer and CRC 
was as high as $22 \%(2,4,8)$. The under-representation of melanoma patients is explained by the fact that the majority of patients with brain metastases from melanoma undergo radiosurgery with or without WBI rather than WBI alone (1).

In the present cohort, we identified two characteristic that were significantly associated with increased occurrence of pre-treatment seizures, namely the number of 1-3 brain metastases and absence of extra-cerebral spread. In addition, a trend was observed for age $\leq 62$ years and an ECOG performance score of $0-1$. Until now, the data from the literature regarding the number of cerebral lesions were conflicting. In a retrospective series of 799 patients, a single lesion was identified as a significant risk factor for seizures in those patients not receiving surgical resection $(p=0.002)$, which was in line with the results of our present study (3). In contrast, in a retrospective study of 565 undergoing resection of brain metastases, preoperative seizures were significantly associated with $>2$ lesions $(p=0.013)(7)$. These data support the idea that the risk factors for seizures vary between different groups of patients with brain metastases and that subgroup analyses are required to properly detect the corresponding prevalence. In another retrospective study of patients receiving neurosurgical resection for brain metastases, age was reported to be negatively associated with pre-operative seizures, which agrees with the above described finding in our study (5). In addition, we have identified extra-cerebral spread as another risk factor. When trying to explain this finding one can only speculate. However, one reason may be the fact that patients with extracerebral metastases very often have other severe symptoms and their prognoses are determined by complications caused by visceral metastases $(1,12,24)$. Therefore, minor seizures may be missed. Extra-cerebral spread is often associated with a poor performance status, which may explain our findings regarding the ECOG score.

Extra-cerebral spread and a poor performance status are generally associated with poorer survival of patients irradiated for brain metastases $(12,24)$. When aiming to tailor a treatment to a patient's situation and needs, the remaining lifespan is an essential aspect. Thus, prognostic factors of survival are important. Therefore, the potential prognostic impact of seizures on survival was investigated in this study. The occurrence of seizures was significantly associated with improved survival at least in the univariate analysis. Such an association has been previously described for glioma patients $(2,25)$. In a large retrospective cohort $(n=1,028)$ including 649 patients with high grade gliomas, seizures were associated with better survival in the entire cohort $(p<0.03)$ and the high-grade group $(p<0.05)$ but not in patients with low-grade glioma $(p>0.2)$ (25). However, seizures were significantly associated with more favorable survival in several retrospective studies of low-grade glioma patients (2).
In the present study, several independent predictors of survival were identified including younger age, female gender, better performance status, lower number of brain metastases, and absence of extra-cerebral spread. These prognostic factors were previously described for patients with brain metastases, which demonstrated consistency of the data of the present study $(11-14,24,26)$. However, the retrospective nature of this study should be considered during the interpretation of its results. This applies also to the previous retrospective studies that investigated prevalence, risk factors and prognostic impact of seizures.

In summary, in the present study the prevalence of pretreatment seizures was $13 \%$. A low number of up to three brain metastases and the absence of extra-cerebral spread were independent risk factors for pre-treatment seizures. Seizures appeared positively associated with survival. Further studies are required to better define the role of pretreatment seizures in patients with brain metastases.

\section{Conflicts of Interest}

On behalf of all Authors, the corresponding Author states that there is no conflict of interest related to this study.

\section{Authors' Contributions}

All Authors participated in the design of the study. D.R., J.W. and L.D. provided data, which were analyzed by D.R. and S.E.S. Interpretation of the data was performed by all authors. D.R., J.W. and S.E.S. drafted the manuscript, which was reviewed and approved in its final form by all Authors.

\section{Acknowledgements}

As part of the project NorDigHealth, this study was funded by the European Regional Development Fund through the Interreg Deutschland-Danmark program (reference: 087-1.1-18).

\section{References}

1 Tsao MN, Rades D, Wirth A, Lo SS, Danielson BL, Gaspar LE, Sperduto PW, Vogelbaum MA, Radawski JD, Wang JZ, Gillin MT, Mohideen N, Hahn CA and Chang EL: Radiotherapeutic and surgical management for newly diagnosed brain metastasis(es): An American Society for Radiation Oncology evidence-based guideline. Pract Radiat Oncol 2: 210-225, 2012. PMID: 25925626. DOI: 10.1016/ j.prro.2011.12.004

2 Englot DJ, Chang EF and Vecht CJ: Epilepsy and brain tumors. Handb Clin Neurol 134: 267-285, 2016. PMID: 26948360. DOI: 10.1016/B978-0-12-802997-8.00016-5

3 Wolpert F, Lareida A, Terziev R, Grossenbacher B, Neidert MC, Roth P, Poryazova R, Imbach L, Le Rhun E and Weller M: Risk factors for the development of epilepsy in patients with brain metastasis. Neuro Oncol pii: noz172, 2019. PMID: 31498867. DOI: $10.1093 /$ neuonc/noz172 
4 Rostami R, Mittal S, Rostami P, Tavassoli F and Jabbari B: Brain metastasis in breast cancer: A comprehensive literature review. J Neurooncol 127: 407-414, 2016. PMID: 26909695. DOI: $10.1007 / \mathrm{s} 11060-016-2075-3$

5 Puri PR, Johannsson B, Seyedi JF, Halle B, Schulz M, Pedersen $\mathrm{CB}$, Kristensen BW and Poulsen FR: The risk of developing seizures before and after surgery for brain metastases. Clin Neurol Neurosurg 193: 105779, 2020. PMID: 32200217. DOI: 10.1016/j.clineuro.2020.105779

6 Ajinkya S, Fox J, Houston P, Greenblatt A, Lekoubou A, Lindhorst S, Cachia D, Olar A and Kutluay E: Seizures in patients with metastatic brain tumors: Prevalence, clinical characteristics, and features on EEG. J Clin Neurophysiol, 2019. PMID: 31856045. DO I:10.1097/WNP.0000000000000671

7 Wu A, Weingart JD, Gallia GL, Lim M, Brem H, Bettegowda C and Chaichana KL: Risk factors for preoperative seizures and loss of seizure control in patients undergoing surgery for metastatic brain tumors. World Neurosurg 104: 120-128, 2017. PMID: 28512046. DOI: 10.1016/j.wneu.2017.05.028

8 Rudà R, Mo F and Pellerino A: Epilepsy in brain metastasis: An emerging entity. Curr Treat Options Neurol 22: 6, 2020. PMID: 32034533. DOI: 10.1007/s11940-020-0613-y

9 Chan V, Sahgal A, Egeto P, Schweizer T and Das S: Incidence of seizure in adult patients with intracranial metastatic disease. J Neurooncol 131: 619-624, 2017. PMID: 27878505. DOI: 10.1007/s11060-016-2335-2

10 Oberndorfer S, Schmal T, Lahrmann H, Urbanits S, Lindner K and Grisold W: The frequency of seizures in patients with primary brain tumors or cerebral metastases. An evaluation from the Ludwig Boltzmann Institute of Neuro-Oncology and the Department of Neurology, Kaiser Franz Josef Hospital, Vienna Wien Klin Wochenschr 114: 911-916, 2002. PMID: 12528323.

11 Gaspar L, Scott C, Rotman M, Asbell S, Phillips T, Wasserman $\mathrm{T}$, McKenna WG and Byhardt R: Recursive partitioning analysis (RPA) of prognostic factors in three Radiation Therapy Oncology Group (RTOG) brain metastases trials. Int J Radiat Oncol Biol Phys 37: 745-751, 1997. PMID: 9128946. DOI: 10.1016/s0360-3016(96)00619-0

12 Rades D, Dunst J and Schild SE: A new scoring system to predicting the survival of patients treated with whole-brain radiotherapy for brain metastases. Strahlenther Onkol 184: 251255, 2008. PMID: 18427755. DOI: 10.1007/s00066-008-1831-5

13 Sperduto PW, Berkey B, Gaspar LE, Mehta M and Curran W: A new prognostic index and comparison to three other indices for patients with brain metastases: an analysis of 1,960 patients in the RTOG database. Int J Radiat Oncol Biol Phys 70: 510-514, 2008. PMID: 17931798. DOI: 10.1016/j.ijrobp.2007.06.074

14 Rades D, Dziggel L, Nagy V, Segedin B, Lohynska R, Veninga T, Khoa MT, Trang NT and Schild SE: A new survival score for patients with brain metastases who received whole-brain radiotherapy (WBRT) alone. Radiother Oncol 108: 123-127, 2013. PMID: 23830191. DOI: 10.1016/j.radonc.2013.06.009

15 Rades D, Dziggel L, Manig L, Janssen S, Khoa MT, Duong VN, Khiem VH and Schild SE: Predicting survival after whole-brain irradiation for cerebral metastases in patients with cancer of the bladder. In Vivo 32: 633-636, 2018. PMID: 29695570. DOI: 10.21873/invivo.11285
16 Janssen S, Hansen HC, Schild SE and Rades D: An instrument for estimating the 6-month survival probability after whole-brain irradiation alone for cerebral metastases from gynecological cancer. Anticancer Res 38: 3753-3756, 2018. PMID: 29848738. DOI: 10.21873 /anticanres.12656

17 Rades D, Hansen HC, Dziggel L, Janssen S and Schild SE: Prognostic role of pre-treatment symptoms for survival of patients irradiated for brain metastases. Anticancer Res 39: 4273-4277, 2019. PMID: 31366517. DOI: 10.21873/anticanres.13591

18 Oken MM, Creech RH, Tormey DC, Horton J, Davis TE, McFadden ET and Carbone PP: Toxicity and response criteria of the Eastern Cooperative Oncology Group. Am J Clin Oncol 5: 649-555, 1982. PMID: 7165009.

19 Abdi H: Bonferroni and Sidak corrections for multiple comparisons. Encyclopedia of measurement and statistics. Salkind NL (ed.). Thousand Oaks, CA, Sage, pp. 1-9, 2007.

20 Tanti MJ, Marson AG, Chavredakis E and Jenkinson MD: The impact of epilepsy on the quality of life of patients with meningioma: A systematic review. Br J Neurosurg 30: 23-28, 2016. PMID: 26982950. DOI: 10.3109/02688697.2015.1080215

21 Avila EK, Chamberlain M, Schiff D, Reijneveld JC, Armstrong TS, Ruda R, Wen PY, Weller M, Koekkoek JA, Mittal S, Arakawa Y, Choucair A, Gonzalez-Martinez J, MacDonald DR, Nishikawa $\mathrm{R}$, Shah A, Vecht CJ, Warren P, van den Bent MJ and DeAngelis LM: Seizure control as a new metric in assessing efficacy of tumor treatment in low-grade glioma trials. Neuro Oncol 19: 1221, 2017. PMID: 27651472. DOI: 10.1093/neuonc/now190

22 Hansen HC, Janssen S, Thieme C, Perlov A, Schild SE and Rades D: Potential impact of the interval between imaging and whole-brain radiotherapy in patients with relatively favorable survival prognoses. Anticancer Res 39: 1343-1346, 2019. PMID: 30842167. DOI: 10.21873/anticanres.13247

23 Hansen HC, Janssen S, Thieme C, Perlov A, Schild SE and Rades D: Whole-brain radiotherapy (WBRT) for brain metastases: Does the interval between imaging and treatment matter? Anticancer Res 38: 6835-6840, 2018. PMID: 30504398. DOI: 10.21873 /anticanres.13057

24 Dziggel L, Segedin B, Podvrsnik NH, Oblak I, Schild SE and Rades D: Validation of a survival score for patients treated with whole-brain radiotherapy for brain metastases. Strahlenther Onkol 189: 364-366, 2013. PMID: 23519358. DOI: 10.1007/ s00066-013-0308-3

25 Lote K, Stenwig AE, Skullerud K and Hirschberg H: Prevalence and prognostic significance of epilepsy in patients with gliomas. Eur J Cancer 34: 98-102, 1998. PMID: 9624245. DOI: 10.1016/s0959-8049(97)00374-2

26 Rades D, Dziggel L, Segedin B, Oblak I, Nagy V, Marita A, Schild SE, Trang NT and Khoa MT: A new survival score for patients with brain metastases from non-small cell lung cancer. Strahlenther Onkol 189: 777-781, 2013. PMID: 23740156. DOI: 10.1007/s00066-013-0362-x 